\title{
Depression among Sesotho speakers in Mangaung, South Africa
}

\author{
NL Mosotho',2, DA Louw'1 ${ }^{1,}$ FJW Calitz², KGF Esterhuyse ${ }^{1}$ \\ 1Department of Psychology, University of the Free State, Bloemfontein, South Africa \\ 2Department of Psychiatry, University of the Free State, Bloemfontein, South Africa
}

\begin{abstract}
Objective: Depression will be the most common mental disorder by 2020 , and it is also expected to be the second leading cause of disability, after cardiac diseases. Moreover, depression is likely to be a major public health burden in the future. This study evaluates the influences of culture on the symptoms of depression among Sesotho speakers. Method: An evaluation of a sample of 100 participants diagnosed with depression was conducted, using the Psychiatric Interview Questionnaire. Results: It was found that depression among Sesotho speakers is manifested in three areas: somatic symptoms, perceptual disturbances and disturbances of the thought processes. Conclusion: Since it has become clear, on the basis of the investigation, that depression is a culturally diverse phenomenon, the authors also recommend that research in this regard should be conducted from a multidisciplinary perspective, so that other paradigms, including those of sociology and anthropology, can also be included.
\end{abstract}

Key words: Depressive symptoms, Culture, South Africa

Received: 08-05-2007

Accepted: 21-08-2007

\section{Introduction}

The World Health Organisation (WHO) predicts that depression will be the most common illness in the world by the year 2020. ${ }^{1}$ It is also expected to be the second leading cause of disability, after heart diseases. ${ }^{2}$ Sartorius reports that depression meets the criteria for classification as a major public health burden. ${ }^{3}$ This is not surprising, since depression has been viewed for many years as the "common cold of mental illness". Despite this alarming situation, there is a paucity of research in this field in developing countries. A major reason for this has been the misconception, until recently, that such countries are relatively free of psychiatric problems, such as depression, which are encountered in industrialised nations. This perception arose from the belief that disorders such as depression were created by the excessive stress that was caused by technological developments. ${ }^{4}$

Until relatively recently, attempts to obtain reliable information on depression in developing countries were

\section{Correspondence:}

DA Louw

Department of Psychology, University of the Free State.

Box 339, Bloemfontein, 9300, South Africa

email: louwda.hum@mail.uovs.ac.za hampered by the fact that in many, if not most cases, the research was conducted by "outsiders". The result was that misinterpretations occurred, owing to language difficulties and deficient knowledge of the cultures that were being investigated. ${ }^{5}$ However, at present the value of cross-cultural research is generally recognised; and there is a greater awareness in respect of flawed research methodologies. It is also acknowledged that, as a result of globalisation, different cultures are becoming integrated, with value and belief systems from one culture being incorporated into other cultures. ${ }^{6}$ Furthermore, research has shown that the "simplistic notion of a black-andwhite world" is no longer defensible (Jackson in Swanbrow). ${ }^{7}$ This implies that even within one culture, several sub-cultures can exist, each with its own relatively unique characteristics. Against this background, Lopez and Guarniccia rightly point out that the primary aim of cross-cultural research is to enhance our understanding of general and culture-specific processes, and particularly the way in which interaction between these variables takes place in a specific context. ${ }^{8}$ As far as depression is concerned, the interaction between culture and depression is multifaceted and complex. ${ }^{5,9}$ Therefore, this correlation is not always easy to assess and interpret. An unfortunate consequence of this is the failure to recognise depressive symptoms, or the misidentification thereof. Cultural competence 
and a thorough understanding of depression are crucial elements to be included in the training of clinicians involved in the mental health field. ${ }^{10}$

\section{Epidemiology}

According to the DSM-IV-TR (APA), the life risk of depression ranges from $10,0 \%$ to $25,0 \%$ in the case of women, and from $5,0 \%$ to $12,0 \%$ in the case of men. ${ }^{11}$ The point prevalence varies from $5,0 \%$ to $9,0 \%$ for women and from $2,0 \%$ to $5,0 \%$ for men. American psychiatrists diagnosed 16,6\% of consecutive admissions as cases of depression, while the rate for a comparable sample in Britain was 46,2\%. ${ }^{12}$ The lifetime prevalence in Germany is 9,0\%; in Canada, 8,6\%; in Taiwan, 16,8\%; in Puerto Rico, 4,6\%; and in South Korea, 3,5\%.13 Other researchers found that the prevalence of depressive illnesses is high in both industrialised and non-industrialised countries. ${ }^{6}$ The prevalence figures for depression revealed by these studies were in excess of $30 \%$ in community samples, while the figures approached $50 \%$ in primary care samples, in settings ranging from rural Lesotho and the slums of Sao Paulo and Santiago in South America, to the general practices of India.

As far as the situation in South Africa is concerned, Laubscher, in one of the first studies in this field, reported that depression was not common among African people. ${ }^{14}$ However, later research has repudiated this claim. For example, Uys, Dlamini and Mabandla found that 13,0\% of psychiatric outpatients in Umtata (Eastern Cape ) suffered from depression. ${ }^{15}$ In research conducted at general practices in the Free State Province of South Africa, Lans, Seane, Gagiano and Joubert and Jordaan and Joubert found a point prevalence of between $6,0 \%$ and $19,0 \%$ in the population of black patients. ${ }^{16,17}$ Moreover, Kale found a point prevalence of 34,0\%, according to the available data. ${ }^{18}$ A study at a South African primary care clinic found that, although 32\% of the attending patients had depressive disorders, the rates of detection by the physicians were consistently low. ${ }^{19}$ Depression is the fourth leading cause of disability in South Africa. ${ }^{20}$

\section{Symptomatology}

The symptoms of depression in the Western world are well known. The American Psychiatric Association (APA) pinpointed the following symptoms, among others: a depressed mood; loss of interest or pleasure in nearly all activities; changes in appetite or weight; a change in sleeping patterns and psychomotor activity; cognitive disturbances characterised by difficulty in thinking and concentrating, or in making decisions; decreased energy; feelings of worthlessness or guilt; and recurrent thoughts of death, or suicidal ideation, plans or attempts. ${ }^{11}$ The World Health Organisation (WHO) lists additional symptoms, such as reduced self-esteem and self-confidence; bleak and pessimistic views of the future; and a marked loss of libido. ${ }^{1}$ Kaplan and Sadock include daily (or sustained) fatigue or loss of energy as one of the common key symptoms in the Western world. ${ }^{21}$

However, it seems that although certain core symptoms are encountered across the different cultures, it is equally true that depressive symptomatology often has unique manifestations in some cultures. ${ }^{8}$ This uniqueness usually finds expression in two ways. Firstly, some symptoms, which are quite common in certain cultures, may be totally absent in others. Secondly, although a specific symptom may appear in several cultures, the intensity of the symptom may vary from culture to culture. In this regard, Young rightly points out that "the lack of consistency in the presentation of depression across cultures tends to decrease the sensitivity of any method used to diagnose this disorder. ${ }^{22}$ For this reason, it is essential for the clinician working with crosscultural populations to become familiar with these variations, in order to accurately assess the patient in whom depression is suspected. The clinician will also find it useful to have a framework for understanding the reason that depression presents as it does across cultures. Most authors agree that, although depression is common in non-Western countries, it manifests differently in these countries. ${ }^{23,24}$ Non-Western patients suffering from depression do not complain of a depressed mood and guilt feelings to the same extent as patients in Western countries. Instead, they tend to project (blame), and complain of somatic symptoms more often; but they rarely manifest suicidal behaviour.

In a widely quoted review article, Singer indicated that depression is common in Nigeria, and is characterised predominantly by somatic presentation. ${ }^{25}$ According to Singer, a similar clinical picture of somatic manifestation is encountered in Senegal, although the Senegalese also display more paranoid and manic symptoms. In Ghana, there is a high frequency of selfaccusation; and patients tend to blame witchcraft for their conditions. In Sudan, feelings of shame seem to supersede feelings of guilt. Swartz points out that research has shown that depressives in West Africa report feelings of guilt less often than is the case in Britain. ${ }^{26}$ However, hallucinations are fairly common among depressive patients in West Africa.

In a study of mental illness in Algeria, which has a strong Arab culture, Al-Issa found that masked depression and delusional depression are the most frequent types of depression encountered by clinicians. ${ }^{27}$ As in other non-Western countries, the manifestation of a depressive mood, in contrast to somatic symptoms, is rare. This could be ascribed to the fact that in most Arab countries, there is a reluctance among people to display a depressive mood, since such a display is regarded as shameful. In the case of delusional depression, delusions of persecution, bewitchment, possession, or poisoning, as well as aggressive forms of behaviour, are common.

The World Health Organisation (WHO), under the supervision of Sartorius, Jablensky, Gulbinat, and Ernberg, launched a study on depression in Canada, Iran, Japan, and Switzerland. ${ }^{28}$ It was found that depression in different social and cultural settings has "core symptoms" such as sadness, joylessness, anxiety and tension, lack of energy, loss of interest, impaired concentration, and a sense of insufficiency, inadequacy, and worthlessness. Moreover, the variations encountered between the groups of patients in the different centres were relatively minor, comprising variations in severity rather than in kind.

One of the recent studies in the field of cross-cultural psychopathology comprised research in which a comparison was made between Chinese psychiatric outpatients and nonpatients in respect of the symptomatology of depression. ${ }^{29}$ The researchers also investigated cultural groups, comprised of Chinese, Chinese American, and Caucasian American students. They found that Chinese psychiatric outpatients, in contrast to non-patients, tend to complain more of somatic symptoms. Unexpectedly, Chinese students manifested significantly fewer somatic symptoms than American students. These findings repudiated the original hypothesis formulated by researchers, 
namely, that Chinese students would display higher rates of somatic complaints than American students would. However, Chinese students did not manifest positive aspects of depression, such as hopelessness, lack of pleasure and lack of happiness, to a significant degree.

Three studies were conducted among Sesotho-speaking depressive patients in the Free State Province, South Africa. 17,13 Although the samples were relatively small, and although there were some differences in the findings, the results obtained by the three researchers concurred in respect of the high incidence of symptoms such as a depressed mood, lack of energy, and thoughts of death and suicide. Swartz also reported symptoms such as dark rings under the eyes, eating and sleeping disorders, tearfulness, loss of weight and fatigue among Xhosaspeaking depressive patients in the Western Cape. Although the patients seemed depressed, they usually did not complain of a dysphoric mood.26

\section{Language and depression}

Our emotions and feelings are usually shaped and expressed by the words we use and our sentence constructions. ${ }^{26}$ The quality of vocabulary also plays an important role in this regard. If language variations or barriers between clinicians and patients are not addressed, they may have a negative effect on the muchneeded communication, and hinder the evaluation and management process. ${ }^{30,31}$ In such a situation, it may be necessary to make use of an interpreter, who should possess special skills, and who should have some experience of working in a mental-health context. The interpreter should be welltrained and properly orientated, since translation can sometimes be a very intricate process, because language expressions, which play a role in revealing our emotional realities, can be very specific in nature. Accurate translation is therefore important.

It is often claimed that certain emotions are expressed more easily in some languages than in others. For example, Manson suggests that the word "depressed" does not exist in the languages of some cultures. ${ }^{32}$ However, the absence of this word does not preclude the existence of depressive illness. Trying to understand depression solely on the basis of a Western language perspective, and assuming that depression does not exist in certain cultures because it is not verbally expressed in the same way, could make the evaluation and treatment process more difficult. ${ }^{24}$ Furthermore, it has been argued that, in contrast with many other cultures, Western cultures place a high value on language that differentiates between emotions, and that compartmentalisation is favoured over a holistic view of the body. ${ }^{19}$

The various ways in which we experience, express and cope with perceived distress are termed "distress idioms". ${ }^{33}$ These idioms of distress refer, inter alia, to variations in the presentation of symptoms across cultures. ${ }^{23}$ Flaskerud argues that there is a relationship between culture, ethnicity, and idioms of distress, because cultural aspects shape symptoms, as well as the mode of distress displayed by depressive patients. ${ }^{34}$ The World Health Organisation (WHO) acknowledges the need to develop a common mental-health language that could be used globally in the field of mental health. If such a language could be used and understood by all concerned, there would be consensus regarding the meaning of all the terms used in describing all mental and neurological conditions and functioning, as well as pathology in a broad sense. However, it is doubtful whether it will ever be possible to create a common international language which is capable of eliminating misunderstandings and omissions. Researchers should nonetheless do their utmost to avoid pitfalls in this regard.

\section{Gender and depression}

One of the factors that have a bearing on the epidemiology of depression, interacting with culture, is that of gender. ${ }^{6}$

Depressive disorders represent the fifth greatest burden for women, and the seventh greatest burden for men, across all physical and mental illnesses. ${ }^{8}$ Gender differences in depression rates emerge in adolescence, and are encountered across cultures. ${ }^{35}$ Although determinants of gender differences in depressive disorders are far from being established, Piccinelli and Wilkinson found that the following factors are likely to be involved: adverse experiences in childhood; depression and anxiety disorders in childhood and adolescence; sociocultural roles with related adverse experiences; psychological attributes related to vulnerability to life events; and coping skills. ${ }^{36}$

In order to contribute to the knowledge base relating to depression in developing nations, especially in Africa, it was decided to conduct a study among Sesotho speakers in the Free State Province of South Africa. In an attempt to avoid a major pitfall of cross-cultural research, namely the language factor, a researcher who is a member of the Sesotho culture, and therefore Sesotho-speaking, conducted the study. The reason for this is that several authors have pointed out that cultural differences in respect of manifestation or symptomatology might be an important factor in the erroneous diagnosis of depression. ${ }^{37}$

\section{Methodology}

The Mangaung Township in Bloemfontein, South Africa, was selected as the geographical area for the conduction of the research. The main reason for this is that the researcher is a member of a mental-health team providing services at different clinics and health establishments in this area. Secondly, Sesotho (the main language spoken in Mangaung) is the mother tongue of the researcher, who is also familiar with the area and the culture. Thirdly, the South African government recommends that researchers should preferably focus on their immediate areas, in order to meet the needs of their own communities.

For this exploratory descriptive study, the participants were comprised of 100 Sesotho speakers diagnosed with depression. They were drawn from a population of patients visiting various health establishments in the area. Patients reporting to a specific health establishment, who qualified during the time period in which the researcher was based at that establishment, were included. The duration of the data-collection was almost four years (January, 2001-October, 2004). The participants were evaluated and diagnosed by a multi-professional team, which generally consisted of a (registered) psychiatrist, a clinical psychologist and a psychiatric nurse (in certain areas, social workers, occupational therapists and/or physiotherapists also formed part of the team). The DSM-IV-TR criteria for major depressive disorders were used as the inclusion criteria. The participants were between 18 and 65 years of age, and both genders were represented. Written informed consent was obtained from each participant.

A semi-structured interview, based on the Psychiatric 
Interview Questionnaire (PIQ) used by the Department of Psychiatry at the University of the Free State, was used to elicit the information. The PIQ is based on the Clinician's Thesaurus: the Guide for Writing Psychological Reports and the Outline of the Psychiatric History and Mental Status Examination. ${ }^{38,39}$ This instrument provides data relating to the following aspects: preliminary identification (including biographical information); main complaints; personal description; history of present illness; psychiatric review of symptoms; previous mental illness; and past personal history, as well as a mental-status examination in respect of: appearance, attitude and behaviour, thought processes, perception, mood and affect, consciousness, orientation, memory, tempo, intelligence, mode of thinking, judgement and insight, and both hypothalamic functioning and autonomic functioning. The PIQ is the standard assessment instrument used by all governmental mental-health establishments in the Free State Province. The present researcher personally conducted the interviews with each individual patient.

Qualitative methods were used to describe the experiences of the participants regarding their symptoms, as well as to elucidate the quantitative data. Qualitative methods consisted of two types of data-collection: open-ended interviews and direct observation. The interview data consist of direct quotations obtained from participants about their experiences, feelings, emotions, opinions and knowledge, while observation data refer to detailed descriptions of participants' activities, behaviours, actions, and the full range of interpersonal interactions and organisational processes that are part of observable human experience. ${ }^{40}$ Individual interviews were transcribed, and the information gathered was grouped into themes. The information was written in the subject's own words, or transcribed as closely as possible (or, in some cases, the subject's account was paraphrased as accurately as possible). The themes were divided into psychological symptoms, physical (somatic) symptoms, as well as behavioural and social symptoms.

Quantitatively, a descriptive statistical analysis was performed to provide indications of the frequency (incidence) of identification of demographic characteristics, signs and symptoms of mental illness, as well as socio-cultural variables associated with depression, as covered by the questionnaire.

The study was approved by the ethics committee and the council of the University of the Free State. The project was also discussed with the Head of the Department of Psychiatry, at the University of the Free State, who is also the provincial clinical head for mental health. He pledged his full support regarding the study. Moreover, permission was obtained from the Head of Health in the Free State Province to conduct this study in the various health establishments. The researcher conducted a pilot study on 40 patients to investigate the practical feasibility of the research. On the basis of the pilot study findings, minor adjustments to the coding of the questionnaire had to be made.

\section{Results}

The results of the study will now be reported, with relevant context discussed. A short summary of the main findings will follow each presentation (tables, figures), after which a comparison of the findings, in relation to other findings, will be presented.

The socio-demographic characteristics of the participants are presented in Table I.

\begin{tabular}{|c|c|}
\hline Characteristics & (\%) of the sample \\
\hline \multicolumn{2}{|l|}{ Age } \\
\hline $18-25$ & 17,0 \\
\hline $26-35$ & 38,0 \\
\hline $36-45$ & 29,0 \\
\hline $46-65$ & 16,0 \\
\hline \multicolumn{2}{|l|}{ Gender } \\
\hline Male & 37,0 \\
\hline Female & 63,0 \\
\hline \multicolumn{2}{|l|}{ Education } \\
\hline None & 1,0 \\
\hline Grades 1-4 & 7,0 \\
\hline Grades 5-7 & 11,0 \\
\hline Grades 8-10 & 14,0 \\
\hline Grades 11-12 & 22,0 \\
\hline Grade 12 plus & 25,0 \\
\hline Other & 20,0 \\
\hline \multicolumn{2}{|l|}{ Marital status } \\
\hline Single & 46,5 \\
\hline Married & 34,3 \\
\hline Separated & 2,0 \\
\hline Divorced & 9,1 \\
\hline Widowed & 5,1 \\
\hline Cohabitation & 3,0 \\
\hline \multicolumn{2}{|l|}{ Employment and occupation } \\
\hline Unemployed and looking for a job & 7,1 \\
\hline Unemployed and not looking for a job & 13,1 \\
\hline Formally employed & 53,5 \\
\hline Informally employed & 6,1 \\
\hline Pensioner & 1,0 \\
\hline Student & 13,1 \\
\hline Disability grant & 6,1 \\
\hline \multicolumn{2}{|l|}{ Religion } \\
\hline Christianity & 94,9 \\
\hline Islam & 1,0 \\
\hline Atheism & 3,0 \\
\hline Other beliefs & 1,0 \\
\hline \multicolumn{2}{|l|}{ Housing } \\
\hline Shack (informal settlement) & 17,2 \\
\hline House/part of a house & 76,8 \\
\hline Traditional dwelling (hut) & 1,0 \\
\hline Outbuildings & 3,0 \\
\hline Combination of buildings & 2,0 \\
\hline \multicolumn{2}{|l|}{ Criminal convictions } \\
\hline Assault & 3,0 \\
\hline Larceny & 1,0 \\
\hline Other crimes & 3,0 \\
\hline \multicolumn{2}{|l|}{ Social support system } \\
\hline Both parents & 9,1 \\
\hline Single mother & 14,1 \\
\hline Single father & 2,1 \\
\hline Grandparents & 9,1 \\
\hline Alone & 19,2 \\
\hline Staying with spouse/own family & 39,4 \\
\hline Staying with friends & 7,1 \\
\hline \multicolumn{2}{|l|}{ Substance abuse } \\
\hline Cannabis & 4,0 \\
\hline Alcohol & 43,0 \\
\hline
\end{tabular}


Fifty-five percent of the participants were 35 years of age or younger. Almost twice as many females as males were included in the study. This finding is not surprising, as previous research and the literature suggest that significantly more women than men complain of depression. Kennedy \& Eisfeld, reported that most mood disorders (excluding bipolar disorder I) are twice as common in females as in males. ${ }^{41}$ This suggestion confirms Gregory's finding that, on average, for every male who suffers from clinical depression in the US, there are two female sufferers, with the female-to-male ratio being 2.4 to 1 , according to the Epidemiologic Catchment Area Research. ${ }^{42}$ In the National Comorbidity investigation, the ratio was 1.7 to 1 . Some subtypes of depression seem to occur three to four times more frequently in females than in males. Another reason for this finding may be the fact that men in the Sesotho culture are not encouraged to express emotions of sadness, depression and grief, amongst others. A Sesotho idiom says: "Monna ke nku ha a lle". Literally, this means that a man is like a sheep, and that he is not supposed to cry.

The educational levels of the sample were surprising, as they were significantly higher than those of the general population in South Africa. The following factors may provide a possible explanation for this somewhat unexpected finding: firstly, the more educated people are, the less likely they are to be concerned or worried about the "stigma" of mental illness, especially depression. Secondly, educated Sesotho speakers may be able to identify and express depressive illness more easily. Thirdly, the less educated people belonging to the traditional cultures tend to visit or consult traditional healers for treatment for their illness, whereas the more educated individuals suffering from physical or mental symptoms prefer to visit Western-trained health professionals. The fact that $55,0 \%$ of the participants were 35 years of age or younger, as previously stated, is not surprising. Since the beginning of the 90s, those who are now in this age group have benefited from the new political dispensation, in which the need for the improvement of educational standards for black people became a major focus in South Africa. It should be taken into account that the "grade-12plus" category also includes persons in possession of post-grade-12 certificates, as well as qualifications other than university degrees.

The majority of the participants were single. This is understandable, in view of the fact that the average age at which South Africans enter into marriage is 30 years. The fact that only half of the participants were formally employed is worrying; however, it should be taken into account that the unemployment rate in South Africa is $41,0 \%{ }^{43}$

With regard to religion, the predominance of Christianity among participants correlates well with the distribution of religious groups in South Africa. The finding that only a minority of the participants lived in an informal settlement confirms the finding, mentioned above, that the sample belonged to the middle- rather than the lower- income group.

Factors associated with the prognosis of mental disorders, such as social support systems, social isolation and co-morbidity in respect of substance abuse (mainly involving alcohol and cannabis), were also considered. Seventy-one percent of the Sesotho-speaking depressive patients had a strong social support system, which rendered the prognosis and course more favourable. As far as substance abuse is concerned, the majority of the participants mentioned that they "used" alcohol, rather than cannabis or other (hard) drugs.
The relationship between stressful life events and depression is indicated in Figure 1.

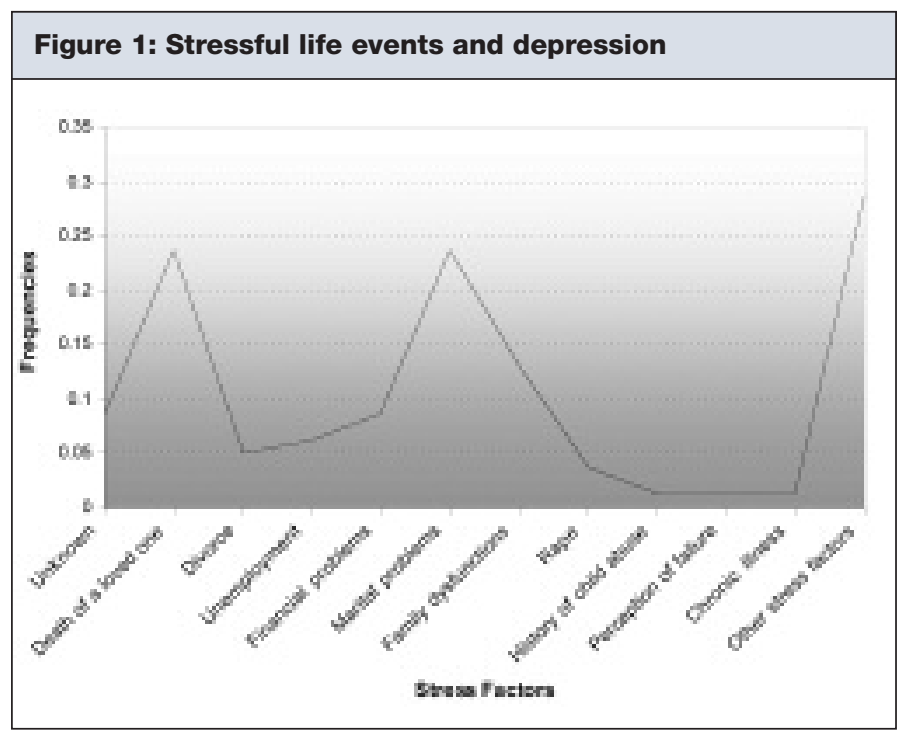

Although in some cases, depression sufferers could not offer an explanation for their disorder, it is apparent that various stress factors played a role in this regard. Examples include the death of loved ones, marital dysfunctions, family dysfunctions, financial difficulties and unemployment.

As far as a history of mental illness in the family (not only including depression) was concerned, the results showed that about 50,0\% of the patients indicated that one or more of their close relatives had been diagnosed at least once with one or more mental disorders. The figures for specific relatives varied as follows: father: 3,0\%; mother: 8,0\%; siblings: 12,0\%; paternal and maternal relatives: $10,0 \%$ and $9,0 \%$ respectively.

The data in Figure 2 show the extent or duration of suffering experienced by people affected by depression in Mangaung.

\section{Figure 2: Duration of symptoms of depression}

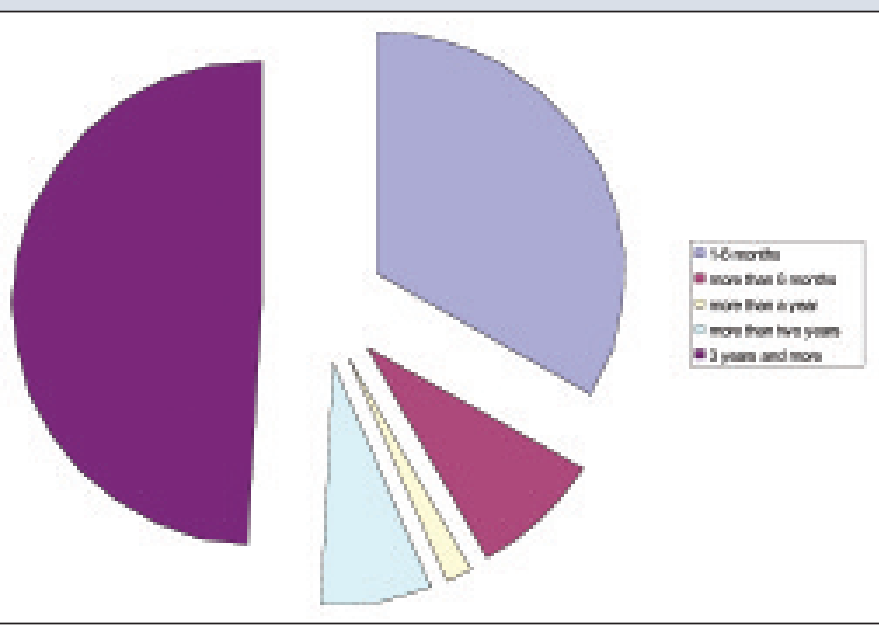

The depressive symptoms of almost 75,0\% of the participants had lasted for longer than 6 months. The reason for this might be that, owing to the prominence and severity of somatic complaints, the clinicians tended to ignore the possibility of psychological dysfunctions or disorders during the initial assessment. 
The findings concerning the primary symptoms and secondary symptoms are presented in Table II. The inclusion criteria for classifying symptoms as primary revealed a prevalence rate of at least $20,0 \%$. The present author realised that dividing the symptoms into physical and psychological categories would lead to overlapping, and would reflect a superficial approach. However, for practical and discussion purposes, it was decided to categorise the symptoms into primary (20,0\% or more) and secondary symptoms (less than $20,0 \%$ ). The frequencies refer to the sum total of the symptoms reported by the participants, as well as those identified by the researcher

\section{Table II: Primary and secondary symptoms among Sesotho} speakers suffering from depression

$\begin{array}{ll}\text { Symptoms } & \text { (\%) } \\ \text { Primary symptoms } & \\ \text { Somatic and autonomic symptoms } & \\ \text { Chest pain } & 39,0 \\ \text { Stiff and painful neck } & 23,0 \\ \text { Fatigue } & 23,0 \\ \text { Headaches } & 86,0 \\ \text { Constipation } & 44,0 \\ \text { Dizziness } & 71,0 \\ \text { Insomnia } & 87,0 \\ \text { Excessive sweating } & 53,0 \\ \text { Decreased appetite } & 56,0 \\ \text { Palpitations } & 65,0 \\ \text { Poor libido } & 77,0\end{array}$

\section{Psychological symptoms}

Irritability

Depressed mood

Loss of interest and pleasure

Grief

Anxiety

50,0

70,0

Suicidal ideas (thoughts) $\quad 49,0$

Memory disturbances $\quad 34,1$

Guilt $\quad 54,0$

Agitation $\quad 36,0$

Shame $\quad 46,0$

Abreaction 21,0

Hallucinations (See Figure 3)

The manifestation of depression among Sesotho speakers seems to have much in common with the manifestation of depression among counterparts in other cultures. As previously mentioned, different cultures share several universal symptoms, such as a depressed mood, suicidal ideas, a lack of interest and pleasure in activities, anxiety, guilt feelings, as well as hypothalamic dysfunctions. However, in the present study, somatic complaints, in terms of both severity and frequencies, comprised the predominant manifestations of depression. These findings are supported by Hollifield et al., who found that in Lesotho, a country that has a direct cultural link with Mangaung, somatic complaints were reported to be more prominent than a depressed mood among patients with depression. ${ }^{4}$ The implication of the present findings is that clinical depression may easily be misdiagnosed, since physical complaints are not always recognised as a manifestation of depression. Another interesting finding was that the participants expressed feelings of guilt somewhat more often than feelings of shame. This differs from Singer's finding that depressive patients in Sudan complained more of shame than of guilt. ${ }^{25}$

A variety of perceptual disturbances also comprised part of the significant symptoms Because of the uniqueness (higher prevalence) of these manifestations among Sesotho speakers, the prevalence of these perceptual disturbances is depicted in Figure 3 .

Figure 3: Perceptual disturbances among Sesotho-speaking depressive patients

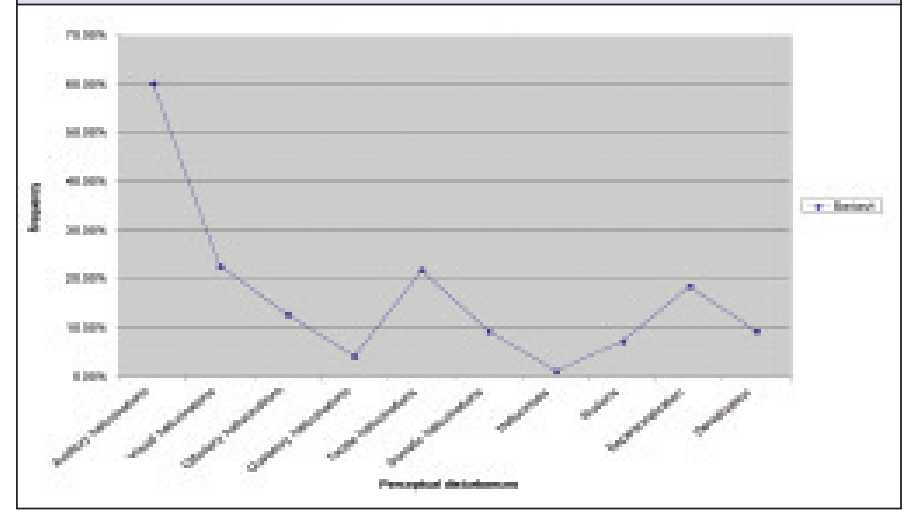

Other notable features of the manifestation of depression among Sesotho speakers included the prevalence of hallucinations, illusions, depersonalisation and derealisation symptoms which are often regarded as indicative of psychotic disorders in the Western world. However, psychotic symptoms may sometimes accompany major depression in Western cultures. ${ }^{44}$ In the present study, psychotic symptoms, especially auditory hallucinations, seemed to be much more prevalent. Some participants complained of experiencing multiple hallucinations simultaneously, while others tended to experience single incidents of hallucinations. These hallucinations were mainly auditory and tactile, but also visual and olfactory. The contents of these hallucinations chiefly comprised: audible voices, which seemed to be calling the patients by their names; hearing the voices of their ancestors; seeing a human shadow passing by; seeing their late loved ones (ancestors); burning sensations; insects crawling over their skins and inside their heads; bells ringing; and hearing music without any external stimuli. The present findings are also confirmed by Littlewood and Lipsedge, who suggest that hallucinations may be considered as a characteristic feature of even minor depression in West Africa. ${ }^{45}$ It also seems that, even within Western cultures, non-Western individuals display significantly more psychotic symptoms. For example, Olfson et al., who investigated the prevalence of psychotic symptoms among outpatients attending an urban general medical practice in New York, where the sample consisted mainly of immigrants from Puerto Rico and the Dominican Republic, found that $20,0 \%$ of the participants were experiencing one or more psychotic symptoms, most commonly auditory hallucinations. ${ }^{46}$ 
Another important finding of the present study was that $55,0 \%$ of the female patients complained of hallucinations, while only $4,0 \%$ of the male patients presented the same symptoms. The higher prevalence of perceptual disturbances among females should not be too surprising, since authors such as Saipanish and Lotrakul have found a similar trend. ${ }^{47}$

The disturbances of the contents of thought processes among Sesotho-speaking depressives were characterised by suicidal ideas, homicidal ideas (4,0\%) and paranoid delusions (14,0\%). Although paranoid delusions were sometimes present, it is critically important to mention that these delusions were not bizarre, as is usually the case with patients suffering from schizophrenia. Indeed, the prevalence of delusions among depressive Sesotho speakers was more than twice the prevalence reported in the findings of the WHO study, which suggested that in all five centres of the study (Montreal, Tehran, Nagasaki, Tokyo and Basle), the prevalence of delusions among depressive patients was less than $5,0 \% .{ }^{28}$ In Algeria, Al-Issa reported that delusions of persecution, bewitchment, possession and poisoning dominated the symptomatology among depressive Algerian patients. ${ }^{27}$

In the present study, as far as disturbances of the form of thought processes were concerned, Sesotho-speaking depressive patients displayed blocking, irrelevant answers and derailment. However, it is important that most of the relevant cognitive symptoms, with the exception of impaired concentration, were neither common nor severe.

The simultaneous presence of both delusions and hallucinations among depressive patients often causes confusion in diagnosis. In this regard, the present researcher strongly agrees with the DSM-IV-TR (2000) that psychotic symptoms among depressive patients should not be dismissed simply because they are viewed as a norm.

The specific health-service providers consulted by the participants are indicated in Figure 4.

\section{Figure 4: Health-service providers consulted by participants}

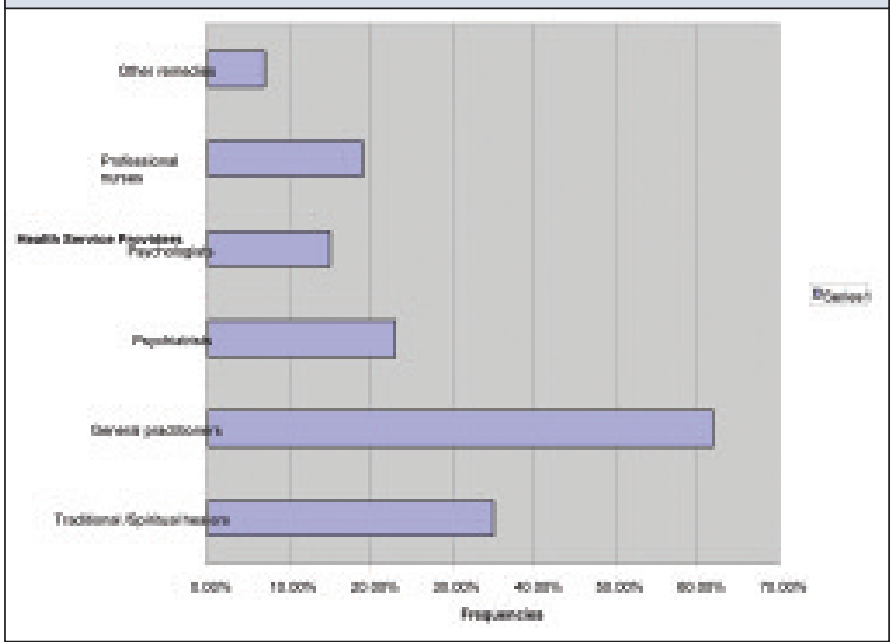

It is significant that, even though the majority of Sesothospeaking depressives did consult the Western-trained health professionals for treatment of their conditions, about one third of the participants indicated that they would still consult the traditional and/or spiritual healers. From the personal interviews, it became apparent that a significant number of these participants would first consult the traditional or spiritual healers in connection with their illness. The number of participants who visited traditional and spiritual healers was lower than the number reported by other South African researchers. ${ }^{48} \mathrm{~A}$ possible explanation for this may lie in the fact that none of the other researchers had focused on one disorder (as in the case of the present study), but had concentrated on the general rate of visits to traditional or spiritual healers for a wide variety of minor ailments. The present study, nonetheless, shows that traditional and spiritual healers do play a significant role in the provision of mentalhealth-care services in South Africa. It is therefore important that their specific roles in the mental-health teams should be clarified by official policies. Moreover, the World Health Organisation (WHO) has called on African governments to officially recognise traditional medicine and to integrate it into their national health systems. The World Health Organisation (WHO) argues that for many centuries, traditional medicine played an important role in combating multiple and complex conditions affecting Africans. Because of the popularity, accessibility and affordability of traditional medicine, more than $80,0 \%$ of the people in the region still continue to rely on it for their health-care needs. ${ }^{49}$

\section{Discussion}

This study confirms the finding of other authors that depressive illness exists across cultures. The Sesothospeaking participants in the present study displayed certain symptoms which are distinctive in terms of their manifestation in the Western world, but which have, nonetheless, been corroborated in other African research.

Different clinical manifestations among Sesotho speakers tend to occur in three areas, in particular: somatic complaints, perceptual disturbances and disturbances of the thought processes. Concerning somatic complaints, the Sesotho speakers who participated in this study complained mainly of headaches, palpitations, a stiff and painful neck, excessive sweating, dizziness, constipation and chest pains. As far as perceptual disturbances were concerned, hallucinations appeared to be more common among the Sesotho speakers than among the subjects whose symptoms were reported on by Western researchers. The contents of these hallucinations included voices which seemed to be addressing the patients; being called by their ancestors; seeing the images of their ancestors; certain bodily sensations; bells ringing; and hearing music. Regarding the disturbances of thought processes, the same patterns occurred as in the case of hallucinations. Sesotho speakers reported suicidal ideas, homicidal thoughts and paranoid delusions. The most common types of these delusions were delusions of reference (entailing the belief that people were talking about them and referring to them) and delusions of persecution (entailing a belief that some people were after them, planning to harm or kill them). Delusions of bewitchment were also present, although these were not very common. However, many "normal" people from various African cultures also experience delusions that their ancestors and spirits have an influence on their behaviour.

However, it is also important to emphasise that a significant number of symptoms among Sesotho-speaking depressives were similar to those described in the DSM-IV-TR. The relevant symptoms included a depressed mood, impaired 
concentration, suicidal ideas, a lack or loss of interest and pleasure in activities, anxiety, fatigue and guilt feelings, as well as hypothalamic dysfunctions. These symptoms tend to overlap cross-culturally, and are labelled "core symptoms" of depression by the World Health Organisation (WHO).

As far as the treatment of depression is concerned, the approach taken by Sesotho speakers is similar to that which is followed by other Africans in the Sub-Saharan regions. Traditional medicine is not disregarded. Some African researchers and scientists argue that mental health care in Africa has been in the hands of both traditional and spiritual healers for centuries. The fact that a significant number of the participants had consulted or visited a traditional or spiritual healer is not out of keeping with African culture and practices. Other participants reported that they simultaneously consulted both traditional and Western-trained practitioners for their ailments.

Whilst the findings of the present study contribute to our understanding of depression within the context of culture, the results should be interpreted with great care, especially as far as generalisation is concerned. For example, the number of female participants was double the number of male participants, which may have affected the extent to which the sample was representative. The same applies to the locality of the research. The participants were almost exclusively from one area in the Free State Province, while Sesotho speakers are widely spread throughout the Free State Province, as well as other regions of South Africa and Lesotho. Another limitation to the generalisability of the findings is that the sample was a biased sample - i.e., it was comprised only of subjects attending health establishments. There are probably many subjects suffering from depression who do not, and/or cannot, go to the health establishments. Thus, the sample is not representative of the general Sesotho community in the area. Sub-cultural differences among Sesotho-speaking groups should also be taken into account. Another significant factor that should not be ignored concerns the educational levels and socio-economic status of the participants. Regarding educational levels: the participants in the present study were fairly well-educated. This may have made it easier for them to identify and express symptoms of depression. As far as socioeconomic status is concerned, people who have financial resources at their disposal are more likely to have access to modern mental-health services than those with limited resources.

\section{Conclusion}

The significance of this study is multifactorial. Not only does the study contribute to important academic data in a field that has been largely neglected in South Africa, but it also provides information on biographical and socio-cultural factors associated with depression among Sesotho speakers. There is no doubt that this research will contribute to the improvement of the reliability of the diagnosis of depression among Sesotho speakers. Thus, the study will also improve our understanding of mental disorders in this culture.

As most mental-health professionals are still trained within the Western diagnostic framework, especially in terms of the DSM-IV-TR and ICD-10, it is clear that certain changes should be made in these training systems, in order to incorporate the cultural differences that were noted in the present study (also see Tanaka-Matsumi \& Chang). ${ }^{50}$ The prevalence of the abovementioned training systems is understandable, since a significant portion of the South African population is part of Western culture. Moreover, Western models such as DSM-IVTR and ICD-10 are also widely accepted in non-Western nations. It is therefore essential that training in these models should be continued, since Western Psychology and Psychiatry have much to offer to Africans who are suffering from various mental disorders. However, it is also time that the unique South African cultures, in all their diversity, began to play a more significant role than is the case at present. By only incorporating either an African or a Western model, not only the training of the psychologists, but also the relevance of the profession, will suffer.

It is equally important that research in South Africa should focus more on epidemiology, especially with regard to the manifestations of mental disorders, in the different cultural groups in the country. Since it has become clear, on the basis of the investigation, that depression is a culturally diverse phenomenon, the authors also recommend that research in this regard should be conducted from a multidisciplinary perspective, so that other paradigms, including those of sociology and anthropology, can also be included. ${ }^{51}$

\section{Acknowledgement}

With thanks to Dr Lyzette Hoffman for editorial assistance

\section{References}

1. World Health Organisation (WHO). The ICD-10 Classification of Mental and Behavioural Disorders: Clinical descriptions and diagnostic guidelines. Geneva: Author, 1992.

2. Holden C. Mental health. Global survey examines impact of depression. Science, 2001; 39-40.

3. Sartorius, N. Inform others of the burden of depression. Organon. n.d.: Accessed on March 5, 2007 from

http://www2.haoyisheng.com/rml/html/page-diye-7.htm

4. Hollifield M, Katon $W$, Spain D, Pule L. Anxiety and depression in a village in Lesotho, Africa: A comparison with the United States. BrJ Psychiatry 1990; 156: 343-350.

5. Kirmayer LJ. Cultural variations in the clinical presentation of depression and anxiety: Implications for diagnosis and treatment.J Clin Psychiatry 2001; 62: suppl 13:22-28.

6. Patel V. Cultural factors and international epidemiology. Br Med Bull 2001; 57: 33-45.

7. Swanbrow D. Black Americans: Study documents differences within community. The University Record Online. 2004. Accessed August 14, 2006 at http://www.umich.edu/ urecord/0304/Jan26_04/02.shtml.

8. Lopez SR, Guarnaccia PJJ. Cultural psychopathology: Uncovering the social world of mental illness. Annu Rev Psychol 2000; 51:571-598. [Electronic version]

9. Lin KM. Biological differences in depression and anxiety across races and ethnic group. J Clin Psychiatry 2001; 62 (suppl 13):13-9.

10. Redmond $M$, Rooney R, Bishop B. Unipolar depression across cultures: A Delphi analysis of the methodological and conceptual issues confronting the cross-cultural study of depression. Aust e-J Advance Ment Health 2006; 5(2). http://www.auseinet.com/journal/voll 5iss2/redmond.pdf

11. American Psychiatric Association (APA). Diagnostic and Statistical Manual of Mental Disorders (DSM-IV-TR). Washington, DC: American Psychiatric Press, 2000. 
12. A1-Issa I. Handbook of culture and mental illness: An international perspective. Madison: International University Press, 1995.

13. Rossouw A. Die voorkoms van major depressie in Botshabelo: 'n Epidemiologies-patogenetiese ondersoek. Unpublished Ph.D. dissertation, University of the Free State, Bloemfontein, 1998.

14. Laubscher BFJ. Sex, custom, and psychopathology in Bantu tribes. London: Routledge \& Kegan Paul, 1937.

15. Uys LR, Dlamini NK, Mabandla SP. A profile of selected psychiatric outpatients in South Africa. Curationis 1995; 1:22-25.

16. Lans BJ, Seane SM, Gagiano EA, Joubert G. Die voorkoms van depressie by swart pasiënte in 'n algemene praktyk. Geneeskunde/The Med J 1994; 4:24-26.

17. Jordaan HL, Joubert G. The prevalence of depression among black patients in a primary care practice. Geneeskunde/The Med J 1994; 7:27-34.

18. Kale R. New South Africa's mental health. BMJ(SA Ed) 1997; 4:577579.

19. Triant VA. The recognition and determinant of depression at a South African primary care clinic. Unpublished Doctor's dissertation. Yale: Yale University School of Medicine, 2002.

20. Feigenoff C. An expanding network in South Africa, 2005. Accessed on November 6, 2006 at

http://transcoder.usablenet.com/tt/oscar.virginia.edu/explorations/x8 199.xml.

21. Kaplan HI, Sadock BJ. Comprehensive textbook of Psychiatry (6th Ed.), volume 1. Baltimore, MD: Williams \& Wilkins, 1995.

22. Young DM. Depression. In W. Tseng \& J. Streltzer (Eds.). Culture and psychopathology: A guide to clinical assessment (pp 29-45). New York: Brunner/Mazel Publishers, 1997.

23. Bhui K, Mohamud S. Cultural adaptation of mental health measures: Improving the quality of clinical practice and research. $\mathrm{Br} J$ Psychiatry 2003;183:185-186.

24. Thakker J, Ward T. Culture and classification: The cross-cultural application of the DSM-IV. Clin Psychol Rev 1998; 5:501-529.

25. Singer K. Depressive disorders from transcultural perspective. Soc SC Med 1975; 9:289-301.

26. Swartz L. Culture and mental health: A Southern African view. Cape Town: Oxford University Press, 1998.

27. A1-Issa I. Culture and mental illness in Algeria. Int J Soc Psychiatry 1990; 3:230-240

28. Sartorius N, Jablensky A, Gulbinat W, Ernberg G. WHO collaborative study: Assessment of depressive disorders. Psychol Med 1980; 10:743-749.

29. Yen S, Robins CJ Lin N. A cross-cultural comparison of depressive symptom manifestation: China and the United States. J Consult Clin Psychol 2000; 6:993-999.

30. Tseng W. Overview: Culture and psychopathology. In W Tseng \& J Streltzer (Eds.). Culture and psychopathology: A guide to clinical assessment. New York: Brunner/Mazel Publishers, 1997. pp. 1-27

31. Tseng W, Matthews D, Elwyn S. Cultural competence in forensic mental health. A guide for psychiatrists, psychologists and attorneys. New York: Bruner-Routledge, 2004.

32. Manson SM. Culture and major depression: Current challenges in the diagnosis of mood disorders. Cult Psychiatry 1995; 3:487-501.

33. Kaiser A, Katz R, Shaw BF. Cultural issues in the management of depression. In S.S. Kazarian \& D.R. Evans (Eds.). Cultural clinical psychology. Theory, research and practice. New York: Oxford University Press, 1998. pp 177-214

34. Flaskerud JH. Ethnicity, culture and neuropsychiatry. Issues Mental H Nurs 2000; 21: 5-29.

35. Murakumi J. Gender and depression: Explaining the different rates of depression between men and women. Perspect Psychol Spring, 2002; 27-34. [Electronic version]

36. Piccinelli M, Wilkinson G. Gender differences in depression. Br J Psychiatry 2000; 177:486-492.

37. Shiraev E, Levy D. Introduction to cross-cultural psychology: Critical thinking and contemporary application. Boston, London, Toronto, Sydney, Tokyo, Singapore: Allyn and Baton, 2001.

38. Zuckerman EL. Clinician's thesaurus: The guide for writing psychological reports (5th ed.). New York: The Guilford Press, 2000.

39. MacKinnon RA, Yudofsky SC. The psychiatric evaluation in clinical practice. Philadelphia: J.B. Lippincott, 1986.

40. Patton MQ. Qualitative evaluation and research methods (2nd ed.). Newsbury Park, London, New Delhi: Sage Publications, 1990.

41. Kennedy SH, Eisfeld BS. Clinical aspects of depression. Clin Corner, Depress 1999; 4: 1-13.

42. Gregory T. Understanding depression in women. Patient Care 1999; 19-34.

43. Statistics South Africa. Census 2001, 2001.

44. Carson RC, Butcher JN, Mineka, S. Abnormal Psychology and Modern Life (1 1 th Ed.). Boston: Ally and Bacon, 2000.

45. Littlewood R, Lipsedge M. Aliens and alienists: Ethnic minorities and psychiatry (3rd ed.). London: Routledge, 1997.

46. Olfson M, Lewwis-Fernandez R, Weisman MM, Gameroff MJ, Pilowsky D, Fuentes M. Psychotic symptoms in an urban general medicine practice. Am J Psychiatry 2002; 8: 1412-1419.

47. Saipanish R, Lotrakul M. Cross-cultural aspects of psychotic symptoms in Thai depressive patients. J Psychiatr Assoc Thai 1999; 44:19-29.

48. Louw DA, Pretorius E. The traditional healer in multicultural society: The South African experience. In L.L. Adler \& B.R. Mukherji (Eds.). Spirit versus scalpel: Traditional healing and modern psychotherapy, 1995. Westport: Bergin \& Garvey. pp. 41-57

49. World Health Organisation (WHO). Traditional Medicine, 2003. Accessed on March 2, 2007 from http://www. who.int/mediacentre/factsheets/fsl 34/en/

50. Tanaka-Matsumi J, Chang R. What questions arise when studying cultural universals in depression? Lessons from abnormal psychology textbooks. In W.J. Lonner, D.L. Dinnel, S.A. Hayes \& D. N. Sattler (Eds.). Online readings in psychology and culture (Unit 9, Chapter 2). Center for Cross-Cultural Research, Western Washington University, Bellingham, Washington USA, 2002. Accessed October 31, 2006 at http://WWW.ac.WWu.edu/ culture/TanakaMatsumiGakuin.htm.

51. Saravanan B, Jacob KS. Culture and insight revisited. Br J Psychiatry 2004; 184:107-109. [Electronic version]. 